\title{
Towards a Complexity-Informed \\ Pedagogy for Language Learning
}

\section{Uma proposta de pedagogia para aprendizagem de línguas na perspectiva da complexidade}

Sarah Mercer*

University of Graz

Graz - Áustria

\begin{abstract}
Focusing on the language classroom, this article attempts to formulate potential principles which could guide, but not prescribe, a complexity-informed pedagogy. To do so, it draws on both existent literature and a consideration of the theoretical framework of complexity for pedagogy. Firstly, the article begins by consolidating key findings from appropriate methodology, postmethod pedagogy, exploratory practice, and ecological perspectives on learning relevant to a complexity perspective. It then continues by explicitly focusing on three sets of key characteristics of complex dynamic systems and suggests potential implications of these for pedagogy: multidimensionality and interrelations, non-linearity and decentralized causality, and dynamism and emergence.
\end{abstract}

KEYWORDS: context-sensitivity; complexity; postmethod; exploratory practice; ecological; group dynamics; relationships.

RESUMO: Com o foco na aula de língua, este artigo tenta formular os princípios potenciais que poderiam orientar, mas não prescrever, uma pedagogia com base na complexidadxe. Para isso, baseia-se tanto na literatura existente quanto na consideração do quadro teórico da complexidade para a pedagogia. O artigo começa com a consolidação das principais conclusōes da metodologia adequada, da pedagogia pós-método, da prática exploratória, e das perspectivas ecológicas na aprendizagem relevantes para a perspectiva da complexidade. Em seguida, discute três conjuntos de características-chave dos sistemas dinâmicos complexos e sugere suas possíveis implicaçôes para a pedagogia: multidimensionalidade e inter-relações, não-linearidade e causalidade descentralizada, e dinamismo e emergência.

PALAVRAS-CHAVE: sensibilidade ao contexto; complexidade; postmétodo; prática exploratória; dinâmica de grupo; relaçōes.

*sarah.mercer@uni-graz.at 


\section{Introduction}

At present, SLA is undergoing what could be termed a 'complexity turn' (MERCER, 2011a) as researchers become increasingly aware of and sensitive to the inherent complexity and dynamism involved in learning and teaching foreign languages. It seems that researchers are now explicitly engaging with what practitioners have always known from their day-to-day experiences in the language classroom; namely, that language teaching is an exceedingly complex undertaking which can be very personal, individual, highly varied, and often difficult to predict in its development. As Tudor (2001, p. 209) suggests, "few practising language educators would seriously question that language teaching is a complex activity".

Therefore, as SLA researchers gain interest in complexity perspectives on language learning and teaching processes, the question arises as to what researchers and theory have to offer in terms of practical, useful insights for language teachers in the classroom, rather than just describing what many experienced teachers already intuitively know. If, as Tarone (2006, p. 163) explains, "classroom language learning and teaching are now both seen as irreducibly complex, and as essentially local and idiosyncratic, so that centralized prescriptions on 'how to teach foreign languages' are unlikely to be universally successful", what then can complexity-based research offer in terms of insights to be of practical service to experienced, less experienced, and novice teachers?

In this article, I seek to explore this question of how complexity perspectives can help inform pedagogy in a practical, yet non-prescriptive, manner. The article has emerged from my own needs as a teacher and researcher to consider the practical implications of my research. Along with McDonough (2002, p. 24), I share the belief that any applied discipline, such as applied linguistics, needs more than simple explanations or descriptions; it requires theories that can inspire practical applications. It is thus crucial to consider what complexity theories have to offer to language educators.

\section{Complexity characteristics}

Under the umbrella of complexity theories are a plethora of related approaches, such as systems theory, chaos theory, complex adaptive/dynamic systems, emergent systems, network theory, non-linear dynamics, among others. However, despite differences, all of them share certain key characteristics. 
Essentially, complexity perspectives describe holistic, organic models composed of multiple systems. A complex dynamic system consists of at least two, but usually a multitude of, interrelated components which may themselves be complex systems. Typically, contexts or the environment, which are themselves conceptualized as systems, are not viewed as external variables affecting a system from outside, but rather are considered to be integral parts of the system. Boundaries between systems are rather blurry, as one system is usually simultaneously part of and subsumed by other systems; therefore, it is virtually impossible to ever comprehend the entire system as potential boundaries and interdependencies are almost infinite. Larsen-Freeman (2012) thus suggests that there needs to be a selection and definition of a system depending on purpose and further suggests considering 'functioning wholes'. In the case of education, this could refer to curriculums, individuals, classrooms, or entire schools. In this article, I will focus on the language classroom as a complex dynamic system, acknowledging, however, that it is also interconnected with multiple other systems beyond the bounds of the classroom and that it can never truly be thought of as existing on its own as if abstracted from its surroundings.

A related characteristic of complex dynamic systems is that these systems are described as being 'open' systems, which suggests they can be affected by influences outside of the immediate system. This means that systems are in a constant state of flux as they adapt to these influences, hence the term used for a certain class of complex systems - 'complex adaptive systems' (see LARSENFREEMAN; CAMERON, 2008, p. 33). The most central defining feature of a complex dynamic system is its dynamism. Everything within the system is dynamic, although this adaptive dynamism may well lead to the system being dynamically stable, in other words, changing but keeping equilibrium or as Larsen-Freeman and Cameron (2008, p. 32) call it, a kind of "stability in motion". The dynamics of the system can also lead to changes in the system as a whole and to the ways in which the components of the system interact. Changes can be gradual over time or sudden, caused by the cumulative effect of multiple factors or single factors, even potentially small perturbations can lead to large changes through what is known as the 'butterfly effect'. As components of the system are interdependent, changes in one part of the system will lead to changes in other parts of the system in ways that are not entirely predictable. This form of change means that complex systems are typically described as being non-linear. In other words, change cannot be 
explained through simple cause-and-effect models. Instead, change emerges from the multiple, interrelated, potentially accumulative nature of interactions between various components of the system. Thus, there is no one single cause of change, but rather causality becomes decentralized (cf. HAGGIS, 2008). There are also certain states and components which represent the preferred states of the system, and which are known as 'attractors' and can 'attract' the trajectory or development path of the system. A final central characteristic of complex dynamic systems is that of emergence. This means that the system functions as an organic whole and that the collective functioning of the interrelated parts of the system cannot be deduced from an understanding of the individual components - typically described by the expression 'the whole is more than the sum of its parts' or at least different to the sum of its parts (LEWIN, 1951 cited in EHRMAN; DÖRNYEI, 1998, p. 14).

In my reading on complexity, it struck me that these characteristics could also aptly describe the language classrooms and the teaching-learning interactions I was working with. Indeed, others have also noted similar comparisons between classrooms and complex dynamic systems (see, e.g., BOWSFIELD, 2004; BURNS; KNOX, 2011; FINCH, 2001; VAN LIER, 1996). Firstly, the number of multiple components interacting and interconnecting within the classroom setting is considerable. There are the sociocultural, educational, and individual cultures that come together, the materials, coursebooks, curriculum, languages, and conditions on a particular day; and even the most complex components of all, the human beings themselves. Each individual learner and the teacher can also be seen as complex dynamic systems; each of whom is unique in their situated socio-psychologies that they bring with them into the classroom interaction.

Secondly, a classroom is clearly an open system, which can be affected by influences from outside the system, such as sociocultural norms, educational policies, technological advances, curriculum constraints, family values, among others. It is also a dynamic environment which is in constant evolution as it adapts to developments occurring within the contexts, such as different compositions of learners, competencies, experiences, resources, days of the week, etc., while aiming continually for the stability of effective, deep learning. In terms of changes in the classroom, any experienced teacher knows that it is rarely one single factor that causes changes in classroom dynamics and learning processes, but rather multiple causes, as is typical of the non-linear and decentralized models of change in complexity models. However, some factors 
may still play a larger role and have a bigger influence on the system as a whole, such as the teachers, the language itself, or even particular students or groups of students, and these could be viewed as 'attractors' in the system. When deciding on pedagogical interventions, it is impossible to attend to everything, but experienced teachers tend to focus on the 'hubs' in the classroom network, in other words, the core components of the system, knowing that when these are affected, there is likely to be an influence throughout the wider system. Teachers are also usually aware that focusing on only one dimension of the complexity in the language classroom will be insufficient to effect change. Instead, they tend to work on creating the momentum to generate change by focusing on several key components, such as their own behavior, learner motivation, teaching materials, and working compositions.

Finally, the characteristic of emergence is especially apparent as the behavior of the class or group as a whole is emergent and depends on the unique, temporally-situated interaction of all the individuals and other components coming together in the classroom. Teachers know that what works well with one group of learners in one context may fail with another group of learners even at the same school, same level of proficiency, and on the same day of the week. Each group generates its own unique emergent behavior which can often be hard to predict.

For these reasons, like others, I have found much resonance between descriptions of complex dynamic systems and my own experiential understandings of language classrooms. However, the question arises as to how these similarities in the descriptive nature of both can be usefully employed to guide pedagogy in ways that remain sensitive to the inherent variation, diversity, and complexity of teaching contexts across the globe. As Tudor (2001, p. 26) explains, "while acknowledging that the complexity of language teaching may bring us closer to the reality of the activity, it also raises a variety of questions, not the least of which is where we should look for the guiding principles we need in order to help us approach our many tasks as teachers, teacher trainers and so on".

\section{Complexity developments in pedagogy}

There have already been several key developments in respect to pedagogy and methodology in applied linguistics, which, while not explicitly being informed by complexity theories, reflect many of the developments associated with complexity. In recent years, there has been much more recognition of the 
diversity of teaching contexts and an understanding that "language teaching is always lived out locally" (TUDOR, 2001, p. 207). There has also been wider acceptance that the reality of life in the language classroom is much more complex than is often presented in official discourse (Ibid, p. 30). Out of the interaction of all the unique and dynamic factors that come together in a language classroom - learners, teachers, materials, methodology, curriculum, cultures, among others - emerges a reality that is "anything but tidy" (op. cit.). As Freeman (1996, p. 107) argues, "the complexity of teaching cannot be cleaned up simply by pretending it is not there; order cannot be forced on to it by writing and talking in a detached manner about its messiness".

As a result, it has become widely accepted that seeking to find a universal pedagogy that suits every unique context is a futile undertaking (BROWN, 2002), and the move has been towards less prescriptive approaches and more principled understandings of learning (ADAMSON, 2004). Rather than aiming to develop a one-size-fits-all approach, researchers have sought instead to generate informed principles for teaching and learning, which can inspire reflection and open up thinking about the appropriacy of methods and materials for specific settings and groups of learners. I will now consider three such approaches and selectively report on some of the ways in which I see them as relating to complexity perspectives and what we can learn from them for a complexity-informed pedagogy.

\subsection{Appropriate methodology}

Perhaps one of the first major steps towards a complexity perspective on pedagogy began with Holliday (1994), who argues that teaching methodologies need to be 'appropriate' to micro and macro level contexts and cultures. In his conceptualization of culture, he defines this as not only referring to whole societies, but also to sections of societies, individual class groups, subject domains, methodologies, as well as personal and family cultures. In a classroom, these multiple cultures interact with each other and form "part of a complex of interrelated and overlapping cultures of different dimensions" (Ibid, p. 28), involving national, educational, individual learners, and teachers. In complexity perspectives, culture itself is seen as being a complex dynamic system. Inspired by ecological perspectives (in SLA, see, e.g., VAN LIER, 2004), complexity theorists often speak of 'nested systems' of interrelated multiple levels of cultures (see, e.g., DAVIS; SUMARA, 2006). However, Holliday's (1994, p. 29) visual representation of the multiple 
cultures in a classroom setting implies less of a hierarchy and instead displays a more complex, interconnected network of systems (cf. DAVIS; SUMARA, 2012). Holliday's understanding of interrelated cultures therefore moves beyond a simple hierarchy of traditional conceptualizations of distinct cultures based on spatial and temporal distinctions (such as sociocultural and institutional), and rather into cultural collectives that stretch across boundaries in time and space. Particularly, in today's language learning landscape, learners are often active members of multiple collectives - real, virtual and imagined. In this way, the learner as an individual is simultaneously part of many systems, which can overlap and interact in an almost infinite number of ways while the learner continues on their learning trajectory.

Holliday's work has thus drawn attention to the role of multiple interacting cultures within the classroom setting and the uniqueness of each context. Indirectly, he portrayed the classroom collective as an 'open system' that can be influenced by multiple other cultural systems, stretching beyond the immediate boundaries of the classroom. Consequently, he argues that effective and 'appropriate' pedagogy can only happen when teaching considers the ways in which these cultures/systems interact and together generate a unique learning context within a specific classroom, which is itself a unique complex dynamic system with emergent properties. Holliday (1994, p. 161) further suggests that the practical implications of an appropriate methodology and recognition of such localized uniqueness and complexity means that it is possible to generalize about some principles, e.g., that classroom cultures are influenced by cultures outside the classroom, but it is not possible to generalize about the precise nature and characteristics of a specific classroom. He concludes that this means that understanding a classroom "is something which has to be worked through in the situation in which teaching and learning have to take place" (Ibid, p. 161). He then proposes that one way of achieving this aim would be for teachers to engage in a form of ethnographic analysis of their language learning context. This would facilitate reflection and continued learning about the practical social situation of any specific classroom to produce 'an appropriate methodology'. It strikes me that such a non-prescriptive, yet principled and context-sensitive approach would form a good basis for any complexity-informed pedagogy. 


\subsection{Postmethod pedagogy}

Inspired by Holliday, Kumaravadivelu $(2001,2006)$ proposed another example of an approach which recognizes the diversity of contexts known as 'postmethod pedagogy'. Kumaravadivelu (2006, p. 165) has suggested that we are currently in the postmethod era, given the widespread recognition that "method is too inadequate and too limited to satisfactorily explain the complexity of language learning and teaching". Instead, he highlights the multitude of factors which are inextricably linked and which together shape and create the content and character of the language learning and teaching context, such as in a language classroom. Essentially, he explains that postmethod pedagogy is a sustainable approach to language teaching, which is sensitive to local particularities involving a critical awareness of local conditions and needs (parameter of particularity), which esteems teachers' own skills in monitoring their teaching practice through reflection and action (parameter of practicality), and which respects and works with the experiences and identities that learners bring with them into the classroom (parameter of possibility) (KUMARAVADIVELU, 2001).

Within such a pedagogical approach, teachers and learners work together as collaborators. As within a complexity perspective, teachers and learners are both parts of the system and the traditional hierarchy of power in the class, with the teacher at the apex, is dispersed suggesting a more democratic classroom structure and diffuse locus of influence. In order to accommodate such a view of the interrelations in the classroom, Kumaravadivelu (2001, p. 545 ) suggests different kinds of autonomy for all participants. As regards the learner, he emphasizes that the postmethod learner is autonomous and can be supported through strategy training and approaches which develop their selfregulatory skills, such as self-evaluation, goal setting, and metacognition. He further suggests that learners need to be socially autonomous in terms of their interpersonal skills. He explains that this kind of autonomy refers "to learners' ability and willingness to function effectively as cooperative members of a classroom community" (Ibid, p. 546). Finally, he refers to a third kind of autonomy, namely, liberatory autonomy, which he views as empowering learners to become critical thinkers - a lifelong skill that is repeatedly being emphasized in various educational contexts (see, e.g., CLAXTON et al., 2011; PUCHTA; WILLIAMS, 2011; WOODWARD, 2011).

Concerning the teacher, he stresses teacher autonomy, which implies that teachers need the confidence and skills necessary to develop their own theories 
of practice responsive to the particularities of their own individual teaching contexts. Specifically, Kumaravadivelu (2001) suggests developing practitioner research using various investigative approaches to gather information about learners and classroom practices, as well as analytical strategies to reflect on these data. Importantly, he stresses that such an undertaking has to be a sustainable long-term way of teaching, rather than an additional burden. Here he refers to work by Allwright (1993) in 'exploratory practice', in which the move is towards an integrated form of practitioner research and exploratory pedagogy - a kind of 'researching as teaching' approach (SMITH; USHIODA; MERCER, 2012). He terms this 'pedagogic exploration' and defines it as an informed method of inquiry in which all the participants observe, reflect, monitor, and then possibly modify their behavior in light of their critical evaluation of what they have noted. Clearly, the degree to which such a form of pedagogy is 'appropriate' will depend on the conditions and expectations emerging from the interaction of multiple local cultures in different settings.

\subsection{Exploratory practice}

Exploratory Practice (EP) is a particular form of postmethod pedagogy (cited by KUMARAVADIVELU, 2006, p. 193-199), which emerged from work initiated by Allwright. As an approach, Allwright (2003, p. 128-130) has defined it primarily in terms of 7 principles which are:

1. Put 'quality of life' first.

2. Work primarily to understand language classroom life.

3. Involve everybody.

4. Work to bring people together.

5. Work also for mutual development.

6. Integrate the work for understanding into classroom practice.

7. Make the work a continuous enterprise.

These principles serve as an epistemological framework for research and pedagogy as opposed to a set of practical procedures that can be reduced to a 'recipe' and again reflect an understanding of a principled way of working in a classroom as opposed to a set of prescriptive procedures. Allwright (2006) also argues that language lessons are 'locally negotiated'. In other words, all participants have an impact both on what happens and on each other, and the 
classroom is the site of multiple complex interactions which generate unique, individual learning conditions.

One of the special characteristics of EP is its focus on 'quality of life'. This means shifting the focus from teaching efficiency in technical terms to considering instead how we can enhance this 'quality of life' in language classrooms for all concerned (GIEVE; MILLER, 2006). This suggests taking a holistic approach to individuals as it highlights how our personal and professional lives are intertwined and how we simultaneously hold multiple identities across various cultures. It also places an emphasis on the nature of the relationships within the group. Crucially, it sees teachers and learners working together collaboratively to better understand their learning and to enhance the quality of life in the classroom. Once again, democratized working relationships between teachers and learners and their mutual interdependence are highlighted in ways which mirror the interconnectedness and decentralized control characteristics of the classroom as a complex dynamic system. These characteristics of EP, such as its holistic perspective, focus on interrelated participants, and sensitivity to contextual and local specifics make the relevance for complexity perspectives immediately apparent.

An additional insight from the EP framework that is relevant for complexity perspectives is that the process of understanding learning, our classrooms, and our learners will never be complete. Due to their inherently dynamic nature, both our classrooms and our learners can be conceptualized as adaptive, open systems which remain open to change and development. Such thinking can guard against our becoming complacent about our learners and our teaching. It can prevent us from labeling and categorizing learners and making assumptions about them and instead can keep us attentive to the potential for change, development, and growth amongst our learners and groups. As a pedagogical approach, it highlights the need for sustainable, flexible, adaptive pedagogies to represent long-term ways of being in the classroom, as opposed to short-term, quick-fix methods. However, as a set of guiding principles, EP can theoretically be conducted on a continuum of strong to weak forms depending on the perceived appropriacy for a specific group and teaching context.

\subsection{Ecological approaches}

Other approaches which offer many useful insights for a complexityinformed pedagogy stem from ecological perspectives on language learning. 
In such approaches, the emphasis is on recognizing the central role played by contexts and environmental factors; as van Lier (2004, p. 5) says "in ecology, context is the heart of the matter". Again these approaches all stress the need to recognize contextual diversity, as well as the interaction of individuals and environmental and contextual factors, leading to unique emergent characteristics in each setting.

Ecological perspectives also draw attention to the relationships among learners, as well as between learners and the environment (van LIER, 2004, p. 258). This therefore places a strong teaching emphasis on interaction, collaboration, and the contextualizing of language and learning (see also van LIER, 1996). One particularly important set of relationships discussed in ecological perspectives is that of 'affordances' (van LIER, 2004, p. 90). These can be understood as the potential relationship between an individual and contextual factors, such as contexts, artifacts, objects, and people, as realized through the person's perception of its utility. From a complexity perspective, it is useful to think of the interconnections in the classroom in terms of relationships, not only between learners and teachers, but also between learners and materials, resources, significant others, and the language itself. In this case, it would be important to enhance learners' relationships with these contextual factors. This suggests the value of raising learners' awareness about the potential offered by resources in the environment for language learning. Here, strategy training and metacognitive work could play an important role in helping learners to become aware of the affordances they could engage with and how. In addition, approaches could be employed which explicitly seek to promote a positive relationship and attitudes towards the language itself and related cultures or communities of use.

Another ecological perspective on language teaching is offered by Tudor (2001). Once again this ecological perspective revisits many of the key themes present in similar approaches outlined above, such as complexity, interrelations, and situatedness, and especially the uniqueness of each teaching situation. He again stresses the need to attend to local realities, not by prescribing general approaches but by considering 'guidelines' for a local understanding of teaching systems in their own right (Ibid, p. 27). He argues that classrooms should not be considered to be "more or less perfect exemplars of an ideal classroom, but rather as complex adaptive systems in their own right". What is special about Tudor's approach is its explicit focus on the dynamic nature of the language classroom and the interactions emerging within it. 
Essentially, the core dynamics and complexities that he is concerned with stem from the active co-construction of the realities of the language classroom through the unique contributions of the teacher and each individual learner. He discusses how the beliefs individuals bring with them to any encounter influence the nature of that learning experience, but that these attitudes are also dynamic and interact with the specifics of each situation over time. In particular, he stresses learner diversity and the impossibility of finding a single methodological approach that will be equally suitable for all individual learners. Instead, he proposes that one way of accommodating such diversity is to ensure "a varied and strategy-rich learning environment" (Ibid, p. 22). He comments explicitly on the potential value of learner-centered and autonomyinformed approaches which can support learners in regulating and co-directing their own learning. For teachers, he too proposes reflective practice as a way of empowering them to examine their own situations, to try to understand the dynamics at work, and then to make decisions to develop an approach to teaching that is locally relevant and appropriate (TUDOR, 2001, p. 26-27). He is careful to explain that understanding is not the solution in itself, but rather it places teachers in the position of being better able to make appropriate, principled, and sustainable decisions about pedagogy appropriate to their specific context, learners, needs, and purposes.

\subsection{Learner diversity}

One of the key dimensions stressed by Tudor as contributing to the complexity inherent in learning-teaching processes is the diversity of the various participants involved, both teachers and, more importantly, the learners. Traditionally, there has been an area of research concerned with learner individual differences, which are defined as "characteristics or traits in respect of which individuals may be shown to differ from each other" (DÖRNYEI, 2005, p. 1). The underlying essence of the work in this area is that there is the potential for great variability amongst learners in terms of their approaches to language learning and relative progress as a direct or indirect result of various learner characteristics. One of the key contributions of this field has been its recognition of the 'uniqueness' of individual learners, as indeed the name of the field suggests.

Ellis (2012, p. 334) proposes that, "the only way that teachers can take account of learner differences is through getting to know the individual learners in their classroom". He goes on to explain this is a gradual process of 
interaction with learners, exploring and experimenting with teaching approaches and observing effects. Adapting teaching approaches to meet the needs and preferences of individual learners in real classrooms "is necessarily a dynamic and experiential process" (ELLIS, 2012, p. 334). In this respect, once again, reflective practice may be a useful way for teaching to seek, as far as it is realistically possible, to recognize and work with such diversity. Learner diversity can also be accommodated by approaches which enable learners to co-direct, select, and make learning personally relevant. In SLA, many familiar approaches have valuable insights and much practical advice to offer as appropriate for specific contexts, for example, learner-centered and negotiated curriculums, experiential learning approaches, forms of strategy training, and self-directed approaches intended to promote learner autonomy.

However, the field of learner individual differences has been dominated by a tension which has resonance in complexity perspectives and which is familiar to any teacher; namely, the tension between a focus on the level of the individual and/or on the group as a whole. As Ushioda (2009, p. 215) explains, much of the research on individual differences has tended to concentrate not on individual learners per se, but rather on the differences and commonalities across groups of learners. More recently, there have been moves away from studies of the "monolithic prototypical faceless learner, whose identity is gross group averages" (DEWAELE, 2005, p. 367) towards more studies of 'real' individual learners and actual 'persons' living 'real' and complex lives (USHIODA, 2009, p. 216).

However, in practical terms, as Tudor (2001, p. 34) explains, "effective teaching depends crucially on teachers being able to tune in to the meaning which language learning has for their students both as individuals and as members of a learning group". Learning is not only an individual personal process, but also a social process. A class is composed of individuals - learners and teacher - and the class has emergent properties, which cannot be understood only by examining the parts separate from the whole. Naturally, understanding the whole (in this case the class) requires an understanding of the component parts of the system (learners, teachers, materials, contextual resources, languages, etc), but it also necessitates an understanding of how they function together as a dynamic whole. As part of a complex dynamic system, a learner simultaneously influences the classroom group through their participation, but they are also influenced by the group (cf. MORIN, 2008). As such, our teaching needs to consider both the individuals as well as the classroom collective. Therefore, although we are already familiar with 
learner-centered and teacher-centered classrooms, complexity perspectives suggest we may need to pay more conscious attention to group-centered teaching (see also classroom-centered teaching; Senior, 2012), which would require a greater understanding of group dynamics (e.g., DÖRNYEI; MURPHEY, 2003) and the nature of collectives.

\section{Complexity-specific perspectives on pedagogy}

Considering these developments with respect to pedagogy, contextsensitivity, and learner diversity, it becomes apparent that applied linguistics is already moving towards complexity perspectives on pedagogy and that there are already many valuable insights to build upon, including also from others who have taken an explicitly complexity perspective on language classrooms (see, e.g., BOWSFIELD, 2004; BURNS; KNOX, 2011; FINCH, 2001; van LIER, 1996). Additionally, there have been other complexity-driven developments with regards to understandings of language, acquisition processes, and other learner internal factors (see, e.g., DÖRNYEI, 2011; ELLIS; LARSEN-FREEMAN, 2009; LARSEN-FREEMAN; CAMERON, 2008; MACINYTRE; LEGATTO, 2010; MERCER, 2011b). It is clearly beyond the scope of this current article to bring all of these strands together, although this would be an essential step for a more comprehensive complexityinformed pedagogy. However, for this article, I would like to focus on the language classroom and consider more explicitly three sets of core complexity characteristics (multidimensionality and interrelations, non-linearity and decentralized causality, and dynamism and emergence) and their potential implications in terms of 'principles' for a complexity-informed reflective practice that seeks to be sensitive to context, diversity, and dynamics.

\subsection{Multiple components and interrelations}

Perhaps the key characteristic of a complex dynamic system is that it is composed of multiple components which are interrelated with each other. Firstly, each individual (teacher and learner) in the class are themselves complex systems made up of a multiple of interconnected cognitive, affective, motivational and social factors, which are situated within multiple 'cultures' and collectives making them 'open' to influences from beyond the bounds of the immediate classroom setting. As teachers, it is important to recognize the holistic lives of our learners and how these can impact on what happens within 
the classroom. As such, it can contribute positively to teacher-learner relationships for us to get to know our learners, find about them as individual holistic beings, and learn about their lives and interests beyond classrooms. This means giving learners the chance to communicate in personally meaningful and relevant ways and share their identities with others. To this end, I have found learner stories, narratives, and autobiographies to be especially useful tools (see MERCER, 2012a); however, we must perhaps be careful not to insist on 'honest' personal accounts by those learners who maybe do not wish to share their own stories and who would perhaps feel more comfortable using their imagination to invent stories of language learning.

As touched upon earlier, while it is important to understand the intrapersonal dynamics of the individuals we work with, we also need to understand the classroom as a whole, and this suggests a focus on the relationships within the system. Within the classroom system, there are many relationships to attend to, such as those between teacher and learners (as individuals and as a collective), amongst learners themselves, between learners and materials, learners and the language, learners and the educational context, etc. This means that teachers have to work consciously at enhancing the relationships between the components in the system, in other words, cultivating positive teacher-learner relationships, inter-group relationships, and the learners' relationships as well as attitudes towards the language, related cultures, materials, resources, and other affordances.

Concerning the inter-personal relationships, an understanding of group dynamics becomes crucial. As Dörnyei and Murphey (2003) state on the cover of their book on group dynamics, "the success of classroom learning is very much dependent on how students relate to each other, what the classroom climate is like, what roles the teachers and learners play and, more generally, how well students can cooperate and communicate with each other". Approaches can include working with collaborative learning structures and cooperative learning designs, which build on some of the principles of group dynamics and have been shown to enhance relationships amongst learners themselves and between the teacher and the learners, as well as promote learner motivation, self-regulation, and positive attitudes towards learning (EHRMAN; DÖRNYEI, 1998). In practical terms, positive group dynamics can be developed by working towards creating a common sense of purpose, class cohesiveness, a sense of belonging, an atmosphere of trust and mutual respect, as well as a shared sense of responsibility for classroom life (see, e.g., DÖRNYEI; MURPHEY, 2003; HADFIELD, 1992). 
As regards teacher-learner relationships, in a complex dynamic system, the teacher is an integral part of the system and therefore shares a different type of relationship than is implied by traditional top-down control models of teaching. Instead, teachers and learners are thought of as working collaboratively together as control is dispersed across the system, although, as a major attractor in the system, teachers still maintain a potentially greater influence on the system as a whole than other components, albeit not one of direct linear control over the system. As any teacher can attest, such a perception of complete, easily predictable teacher control over an entire class all the time is at best illusory, given the multiple components and processes at work in any classroom at any one point. However, the role and behavioral expectations and interactional structures of many classroom cultures do still mean that teachers are likely to remain one of the key influences within the system.

A useful pedagogical perspective embracing more collaborative kinds of relationships can be found in experiential approaches (see, e.g., KOHONEN, 2000), which are more participatory and learner-centered involving learners as active agents in the construction of their own learning. It conceives of teachers as facilitators and draws attention to what learners bring with them to the classroom and how their experiences can be incorporated as part of the learning process. It requires reflection and a metacognitive awareness to facilitate learner agency and empower learners to become autonomous and self-directed. It echoes a perspective on classrooms as learning communities, as presented by Watkins (2005, p. 21), who also emphasizes the forms and qualities of relationships within classrooms as people come together for the shared purpose of learning. He describes learning communities as being collectives "in which each member is an active participant, a sense of belonging has developed, collaboration between members of the community is frequent, and diversity of members is embraced" (the ABCD of his model of learning).

Focusing on the relationships between the participants in the classroom highlights the social nature of learning, the importance of the quality of the learning climate and group dynamics, in addition to the role of conversation, dialog and interaction among participants (see also van LIER, 1996). This suggests that an important task for teachers is enhancing the emotional climate of the classroom and the quality of the relationships within it. As Stevick (1980, p. 4) explained, successful language teaching depends "less on materials, techniques and linguistic analyses, and more on what goes on inside and between the people in the classroom". Clearly, such a view of pedagogy is 
reminiscent of various humanistic approaches to language teaching (e.g., MOSKOWITZ, 1978). In general, "relationship-centred teaching values difference and diversity, authentic responsive participation, shared decisionmaking, collaboration, partnership, and awareness of self and other. The role of the teacher becomes one of co-evolution rather than giver of information" (MENNIN, 2010, p. 164).

\subsection{Non-linearity and decentralized causality}

Other central characteristics of a complex dynamic system are its nonlinear dynamics and decentralized control. As most teachers know from experience, "teaching does not cause learning" and "a learning act' never automatically or necessarily follows a 'teaching act”' (van LIER, 2004, p. 196). Learning can take place at any time, at different paces for different individuals and is not caused by one single thing. Rather multiple factors can cumulatively lead to learning - some of which are more easily identifiable and predictable, others less so. However, both teachers and learners share the same purpose, namely, for learners to learn as well as possible.

As control is viewed as being decentralized in a complex dynamic system, it means that not just the teacher or even necessarily the teacher can affect the life and learning in the classroom system; rather it can be generated from all parts of the system, such as individual components or a combination of components. This implies a different classroom structure to the traditional concept of a hierarchy and instead suggests a form which sees both teachers and learners co-contributing to the success of the classroom life and interactions. Decentralized causality also points to the value of taking a holistic perspective of the classroom and recognizing the agency of all the individuals and the collective agency of the group together. In order to enhance learning, teachers can focus on creating 'momentum' for development and change (cf. DAVIS; SUMARA, 2006). As it is impossible to attend to every detail in a classroom, it is more efficient to concentrate primarily on those factors that are known to be core components of the system - hubs where the effect of any change is more likely to spread throughout the system. In the case of the classroom, these include class climate, group dynamics, motivation, and positive relationships to individuals, as well as resources and the language itself. Nevertheless, the dynamics of a complex system mean that, at times, small changes can also lead to larger, tangible effects in the classroom, such as with the 'butterfly effect'. It is therefore worth considering the potential impact on 
classroom dynamics and relationships of more micro-level decisions, such as the choice of teacher language, forms of praise and feedback, explicitness of instructions, seating arrangements, appearance of the classroom, etc. (see, e.g., CLAXTON et al., 2011; van LIER, 1996).

An understanding of non-linearity also shifts our attention from causes of change to the effects of change. As suggested in the methodological approaches outlined above, reflective practice could be a useful way for teachers to remain flexible and adaptive to the ongoing dynamics in the language classroom by critically observing and reflecting on the processes in the classroom (see, e.g., FARRELL, 2007). While many experienced teachers will use their experienced-based knowledge and intuitions in their reflection and evaluation, it may help others, especially less experienced or novice teachers, to have an explicit complexity-informed framework as a conceptual and analytical tool to aid reflection and foster localized understandings of the classroom as a system. For teacher training, rather than simply working with a transmission model of supposed pedagogical theory and knowledge, it indicates the value of an approach which also supports trainee teachers in developing their critical reflective skills to generate their own context-sensitive and locally appropriate approaches to teaching (KUMARAVADIVELU, 2006, p. 217). As Tudor (2001, p. 209) explains, trainee teachers need to be empowered with the confidence to acknowledge and analyze the complexity of language teaching without the fear of this being interpreted as a sign of having failed to meet the idealized, neat conceptions of supposed teaching practice that they are often presented with.

\subsection{Dynamism and emergence}

The final key characteristics to be considered are those of dynamism and emergence which have in part already been covered in the other sections. Essentially, in the language classroom, the concept of emergence helps us to appreciate that that the classroom as a whole cannot be fully understood from a consideration separately of its component parts. As Dörnyei \& Murphey (2003, p. 3) explain, groups have 'a life of their own', and, as a social unit, a group is bigger and different to the sum of its parts. This emphasizes the importance of developing group identities, as well as the fact that learning can be also shared (DAVIS; SUMARA, 2006, p. 144) and that agency can be collective (BANDURA, 2000). 
The concept of emergence also helps us to appreciate why even the best made lesson plans can work out quite differently in reality and highlights the difficulty of predicting the behavior of the classroom system, as no two classes are ever exactly the same. However, research on expertise in teaching has shown that while recognizing the uniqueness and diversity of each learning-teaching encounter, expert teachers are also able to recognize patterns in the dynamics and emergent situations in classrooms and thus act accordingly (BERLINER, 2004). In this case, more practitioner classroom-based research would be needed to help make the patterns, skills, and knowledge held by expert teachers explicit. Nobody is better placed than teachers themselves, who are all too aware of the complexity they face on a daily basis, to further our understandings of emergent classroom complexity. If complexity research and theory wish to make concrete contributions to language teaching pedagogy, then this will ultimately be best achieved in cooperation with actual teachers working in a wide range of contexts.

Finally, the dynamism of both learning and the development of the classroom dynamic, especially their non-linear progression, imply a focus on the processes of learning, rather than concentrating on end products or results of teaching. Indeed, the word 'process' already underscores the inherent dynamism, fluidity, and continuity of learning as opposed to the static conceptualization inherent in the word 'result'. Concentrating on the process of learning draws attention to the potential for progress and improvement for every learner, rather than setting the same static end goal for all. It mirrors work done on growth mindset thinking and attitudes (DWECK, 2006) in which language learning ability is not viewed as a static, fixed entity but as a potential that can be developed to differing degrees depending on the complex interaction of a range of variables (MERCER, 2012; MERCER; RYAN, 2010). This reflects a dynamic, process-oriented view of learning and is essentially a more optimistic and positive view of learning. It also helps us and our learners to appreciate the nature of mistakes and regressions as inherent parts of the learning process. Concentrating on the process and potential for change can help us to avoid assigning learners and or entire classes static labels about their style, personalities, and competences, and, instead, sensitizes us to the potential for growth and improvement in every class and learner. 


\section{Conclusion}

Many of the recent developments in applied linguistics (e.g., appropriate methodology, postmethod pedagogy, exploratory practice, learner-centeredness, autonomy, experiential learning, collaborative learning structures, negotiated curriculum, reflective practice, among others) already reflect an implicit understanding of the complexity inherent in the language learning-teaching processes. This article has sought to consolidate some of these insights and consider additional practical principles that can be gained from considering the language classroom from a complexity perspective. Clearly, as has been cautioned by others (e.g., HOLLIDAY, 1994; TUDOR, 2001), while these principles can help educators to reflect on the possible nature of and dynamics of their classrooms, they can never, and are not intended to, provide specific answers to the particular challenges facing individual classrooms nor are they intended to prescribe a supposed 'ideal' universal form of pedagogy. Instead, they reflect this author's interpretation of the complexity framework for pedagogy, and it is hoped that they may serve as guiding principles or simply food for thought for others. Ultimately, each 'messy' and unique classroom will require its own local teaching strategies and procedures as appropriate for its individual composition and settings.

Perhaps, as has been my own case so far, the key contribution of complexity perspectives lies in their potential to prompt alternative ways of thinking and open our eyes to different ways of viewing our classrooms. They have caused me to question and critically examine my assumptions about aspects of learning and teaching that were unwittingly conceptualized in terms of simplistic, unidirectional, linear patterns and have engendered a greater awareness on my part of the need to be flexible, adaptive, and sensitive to the dynamics in the classroom. Essentially, complexity perspectives on pedagogy reflect many humanistic principles (cf. LARSEN-FREEMAN, 2012), as they allow us to work with, embrace, and value individual diversity, human relationships, contextual sensitivity, and the quality of life in the classroom for all the participants.

\section{Acknowledgement}

I would like to take this opportunity to thank the anonymous reviewers for their thoughtful and careful feedback. I would also like to thank Alan Waters for comments on an earlier draft. All errors and omissions are entirely my own. 


\section{References}

ADAMSON, B. Fashions in language teaching methodology. In: DAVIES, A.; ELDER, C. (Ed.). The Handbook of Applied Linguistics. Oxford: Blackwell, 2004. p. 614-622.

ALLWRIGHT, D. Exploratory Practice: Rethinking practitioner research in language teaching. Language Teaching Research, v. 7, n. 2, p. 113-141, 2003.

BANDURA, A. Exercise of human agency through collective efficacy. Current Directions in Psychological Science, v. 9, n. 3, p. 75-78, 2000.

BERLINER, D. C. Expert teachers: Their characteristics, development and accomplishments. In: BATLLORI I OBIOLS, R.; GOMEZ MARTINEZ, A. E; OLLER I FREIXA, M.; PAGES I. BLANCH, J. (Ed.). De la teoria... a l'aula: Formacio del professorat ensenyament de las ciències socials. Barcelona, Spain: Departament de Didàctica de la Llengua de la Literatura I de les Ciències Socials, Universitat Autònoma de Barcelona, 2004. p. 13-28.

BOWSFIELD, S. Complexity in the English language arts classroom: Prompting the collective. In: COMPLEXITY SCIENCE AND EDUCATIONAL RESEARCH CONFERENCE, 2, 2004, Kingston, Ontário, Proceedings... Kingston, On: University of Kingston, 2004. Available at: <http://www. complexityandeducation.ualberta.ca/conferences/2004/Documents/CSER2_ Bowsfield.pdf $>$. Acessed in: October, 22, 2012.

BROWN, H. D. English language teaching in the "post-method" era: Towards better diagnosis, treatment, and assessment. In: RICHARDS, J. C.; RENANDYA, W. A. (Ed.). Methodology in Language Teaching: An Anthology of Current Practice. Cambridge: Cambridge University Press, 2002. p. 9-18.

BURNS, A.; KNOX, J. Classrooms as complex adaptive systems: A relational model. TESL-EJ, v. 15, n. 1, p. 1-25, 2011.

CLAXTON, G.; CHAMBERS, M.; POWELL, G.; LUCAS, B. The Learning Powered School. Bristol: TLO Limited, 2011.

DAVIS, B.; SUMARA, D. Complexity and education: Inquiries into learning, teaching and research. London: Routledge, 2006.

DEWAELE, J.-M. Investigating the psychological and emotional dimensions in instructed language learning: Obstacles and possibilities. The Modern Language Journal, v. 89, n. 3, p. 367-380, 2005

DÖRNYEI, Z. The Psychology of the Language Learner. Hillsdale, NJ: Erlbaum Associates, 2005. 
DÖRNYEI, Z. Researching complex dynamic systems: 'Retrodictive qualitative modelling' in the language classroom. Language Teaching. First View. p. 1-12, 2011. Available at: http://dx.doi.org/10.1017/S0261444811000516. Acessed in: January, 27, 2013.

DÖRNYEI, Z.; MURPHEY, T. Group dynamics in the language classroom. Cambridge: Cambridge University Press, 2003.

DWECK, C. S. Mindset: The New Psychology of Success. New York: Random House, 2006.

EHRMAN, M. E.; DÖRNYEI, Z. Interpersonal dynamics in second language acquisition. Thousand Oaks: Sage, 1998.

ELLIS, N. C.; LARSEN-FREEMAN, D. Language as a complex adaptive system. Language Learning, v. 59, suppl. 1, p. 1-26, 2009.

ELLIS, R. Language Teaching Research and Language Pedagogy. Chichester: John Wiley and Sons, 2012.

FARRELL, T. S. C. Reflective language teaching: From research to practice. London: Continuum, 2007.

FINCH, A. E. Complexity in the language classroom. Secondary Education Research, v. 47, p. 105-140, 2001. Available at: <http://www.finchpark.com/ arts/complexity.pdf>. Acessed in: October, 22, 2012.

FREEMAN, D. Redefining the relationship between research and what teachers know. In: BAILEY, K. M.; NUNAN, D. (Ed.). Voices from the language classroom. Cambridge: Cambridge University Press, 1996. p. 88-115.

GIEVE, S.; MILLER, I. K. What do we mean by 'quality of classroom life'? In: GIEVE, S.; MILLER, I. K. (Ed.). Understanding the Language Classroom. Basingstoke: Palgrave Macmillan, 2006. p. 18-46.

HADFIELD, J. Classroom dynamics. Oxford: Oxford University Press, 1992.

HAGGIS, T. 'Knowledge must be contextual': Some possible implications of complexity and dynamic systems theories for educational research. In: MASON, M. (Ed.). Complexity Theory and the Philosophy of Education. Chichester: WileyBlackwell, 2008. p. 150-168.

HOLliDAY, A. Appropriate Methodology and Social Context. Cambridge: Cambridge University Press, 1994.

KOHONEN, V. Towards experiential foreign language education. In: KOHONEN, V.; JAATINEN, R.; KAIKKONEN, P.; LEHTOVAARA, J. Experiential Learning in Foreign Language Education. Harlow: Pearson Education, 2001. p. 8-60.

KUMARAVADIVELU, B. Toward a postmethod pedagogy. TESOL Quarterly, v. 35, p. 537-560, 2001. 
KUMARAVADIVELU, B. Understanding Language Teaching: From Method to Postmethod. Mahwah, NJ: Lawrence Erlbaum, 2006.

LARSEN-FREEMAN, D. Complex dynamic systems: A new trandisciplinary theme for applied linguistics? Language Teaching, v. 45, n. 2, p. 202-214, 2012. LARSEN-FREEMAN, D.; CAMERON, L. Complex Systems and Applied Linguistics. Oxford: Oxford University Press, 2008.

LEWIN, K. Field theory in social science. New York: Harper \& Row, 1951.

MACINTYRE, P. D.; LEGATTO, J. J. A dynamic system approach to willingness to communicate: Developing an idiodynamic method to capture rapidly changing affect. Applied Linguistics, v. 32, n. 2, p. 149-171, 2011.

MCDONOUGH, S. Applied Linguistics in Language Education. London: Arnold, 2002.

MENNIN, S. Teaching, learning, complexity and health professions education. JIAMSE, v. 20, n. 2, p. 162-165, 2010.

MERCER, S. The self as a complex dynamic system. Studies in Second Language Learning and Teaching, v. 1, n. 1, p. 57-82, 2011a.

MERCER, S. Language learner self-concept: Complexity, continuity \& change. System, v. 39, n. 3, p. 335-346, 2011 b.

MERCER, S. Working with learner histories. Presented at IATEFL Research SIG PCE, 2012a. Available at: <http://resig.weebly.com/resources.html>. Acessed in: July, 25, 2012.

MERCER, S. Dispelling the myth of the natural-born linguist. ELT Journal, v. 66, n. 1, p. 22-29, 2012b.

MERCER, S.; RYAN, S. A mindset for EFL: Learners' beliefs about the role of natural talent. ELT Journal, v. 64, n. 4, p. 436-444, 2010.

MORIN, E. On complexity. Cresskill, NJ: Hampton Press, 2008.

MOSKOWITZ, G. Caring and sharing in the foreign language classroom. Rowley: Newbury House, 1978.

PUCHTA, H.; WILLIAMS, M. Teaching young learners to think. Innsbruck: Helbling, 2011.

SENIOR, R. M. Class-centred teaching: A framework for classroom decision making. In: BURNS, A.; RICHARDS, J. C. (Ed.). The Cambridge guide to pedagogy and practice in second language teaching. Cambridge: Cambridge University Press, 2012. p. 38-45.

SMITH, R.; USHIODA, E.; MERCER, S. How to combine teaching and researching: Focus on the learner. IATEFL Pre-Conference Research SIG Event. 2012. 
STEVICK, E. Teaching languages: A way and ways. Rowley: Newbury House, 1980 .

TARONE, E. Language lessons: A complex, local co-production of all participants. In: GIEVE, S.; MILLER, I. K. (Ed.). Understanding the Language Classroom. Basingstoke: Palgrave Macmillan, 2006. p. 163-174.

TUDOR, I. The Dynamics of the Language Classroom. Cambridge: Cambridge University Press, 2001.

USHIODA, E. A person-in-context relational view of emergent motivation, self and identity. In: DÖRNYEI, Z.; USHIODA, E. (Ed.). Motivation, Language Identity and the L2 Self. Bristol: Multilingual Matters, 2009. p. 215-228.

VAN LIER, L. Interaction in the language curriculum: Awareness, autonomy and authenticity. Harlow: Pearson Education, 1996.

VAN LIER, L. The ecology and semiotics of language learning. Dordrecht: Kluwer, 2004.

WOODWARD, T. Thinking in the EFL class. Innsbruck: Helbling, 2011.

Recebido em 26/07/2012. Aprovado em 04/10/2012. 